\title{
Bridging the Digital Divide: Case Study of the Distribution of Tablets to First Years at the University of Johannesburg
}

\author{
Zenia Barnard \& Derek van der Merwe \\ University of Johannesburg, Center for Information and \\ Knowledge Management, Faculty of Management, \\ Johannesburg, South Africa
}

zenia@zeniabarnard.com dvandermerwe@uj.ac.za

\begin{abstract}
The digital divide between those more and those less technologically skilled is a reality and has been for many years. This divide is especially prominent in developing countries such as South Africa and in societies that suffer from socio-economic disadvantage. There are many reasons for the continued presence of this divide and these are briefly described in this paper. The negative consequences that flow from this divide, is also briefly discussed. It is not only social and economic deprivation, though, that contribute to the divide. A project at the University of Johannesburg (UJ) to provide tablets to first year students is discussed in some detail. The challenges that arose from the implementation of this initiative make it apparent that factors such as psychology and managerial efficiencies also contribute in no small measure to a perpetuation of the divide. A multi-disciplinary approach to the eventual bridging of the divide is proposed. Such an approach takes account of the need to recognize and develop a host of solutions as necessary preconditions for sustainable technological advancement in developing countries.
\end{abstract}

Keywords: digital divide, tablet distribution, higher education, developing countries, multidisciplinary

\section{Introduction}

The information explosion triggered by the Information Age since the late 1960's has captured the imagination of many. This has led, and continues to lead, to a constant endeavour to find better, newer and faster methods by means of which to share information and to communicate. The development of technology to optimize the dissemination by digital means of information and

Material published as part of this publication, either on-line or in print, is copyrighted by the Informing Science Institute. Permission to make digital or paper copy of part or all of these works for personal or classroom use is granted without fee provided that the copies are not made or distributed for profit or commercial advantage AND that copies 1) bear this notice in full and 2) give the full citation on the first page. It is permissible to abstract these works so long as credit is given. To copy in all other cases or to republish or to post on a server or to redistribute to lists requires specific permission and payment of a fee. Contact Publisher@InformingScience.org to request redistribution permission. communication systems is relentless.

Superior skills are required to create and use digital information and communication systems, skills acquired through advanced education and knowledge and exposure to substantial resources. Acquisition of these skills and the technical resources they require translates inevitably into an acknowledgment of prosperity and privilege. 
A world without technology is unthinkable for any modern, ambitious individual or organisation that strives to hold its own in a competitive and ever-changing environment. Although the complicated technical functioning of digital tools is often an arcane mystery to end-users, technology in general simplifies and advances business management and administration. It saves an organisation time, money and effort, commodities that can be channelled into further benefit for the organization. On a personal level, these tools also help individuals to become active citizens of the global community by creating interactive channels of communication.

This constant search for cutting-edge technology, however, has created a dynamic cycle of regeneration and evolution. This cycle is responsible for the advancement, growth and information revolution in the civilised world. However, it is also responsible, directly and indirectly, for regression and deterioration in those societies that have been unable to establish or to materially benefit from sophisticated ICT infrastructure. Jeffrey Sachs (Campbell, 2001) confirms this by stating that

"Today's world is divided not by ideology but by technology... A small part of the globe, accounting for some 15 per cent of the earth's population, provides nearly all of the world's technological innovations. A second part, involving perhaps half of the world's population, is able to adapt these technologies in production and consumption. The remaining part, covering around a third of the world's population, is technologically disconnected, neither innovating at home nor adopting foreign technologies."

\section{The Digital Divide Endures in South Africa}

The term "digital divide" refers to the gap that exists between those people who have access to, as well as the skills to operate, information and communication technologies, and those who have no access to these technologies, who may not even be aware of their existence and/or do not have the skills and/or resources to utilise them (Cullen, 2001; Antonio \& Tuffley, 2014). This gap could stretch across certain countries that differ in their degree of development, or it could exist between people in the same country who find themselves in different (financial, social, educational, etc) situations or stages of development. The information and communication technologies referred to include telephones, computers, the Internet, televisions, cell phones, fax machines, etc. The digital divide also refers to differences in the nature and modes of access to the Internet, utilisation of the Internet and other ICTs that underpin the electronic transfer of information in digital format and is often measured in terms of the level of Internet penetration (Campbell, 2001; Charp, 2001). There is an implied benefit in this definition in terms of the inherent requirement for access to such technologies, and a resultant disadvantage for not having these resources available. Although these authors wrote in 2001, the same conditions for the digital divide still obtain, alarmingly so (Kularski \& Moller, 2012).

It is abundantly clear that developing, technologically less advanced countries are at a distinct disadvantage in respect of the exposure to and use of technology, as a large percentage of the population in these countries lack access to what would, in developed countries, be perceived as "mundane" ICTs, such as the telephone and even the radio (Cullen, 2003). The most obvious reason for this is the drastic shortage of resources for the acquisition and maintenance of the equipment required to create the necessary infrastructure (Mansell, 2002).

This divide can be observed on a large scale when comparisons are drawn between countries: in contrast with the fast pace at which countries such the United States and Great Britain develop technologically, the patent underdevelopment of many countries in Africa, Asia and Oceania becomes increasingly apparent (Barnard, 2005). Apart from the lack of financial support from the governments of these disadvantaged countries, the lack of infrastructure, training facilities and knowledge goes a long way towards explaining this sorry state of affairs (Warshauer, 2002). The 
problem does not only exist on a macro-level. Every country (even the most developed and privileged) also experiences a further split/divide between those inhabitants who are technologically advanced and those who are not (Mansell, 2002: 2).

At the core of the digital divide, therefore, is the fact that technological change occurs in an uneven manner, and although progress is rapid, the diffusion of technology is always less so (Campbell, 2001). In addition, the conditions for optimum development of ICTs in a particular region or in a particular society may be less than favourable (Barnard, 2005). Most authors' concerns in terms of the divide are that the world would become divided along the lines of the "information rich" and the "information poor" (Goodrick \& Srivastava, 2002), with the resultant consequences of creating a socio-economic divide (Centre for Democracy \& Technology, 2001). The divide grows rather than lessens over time. The fundamental desire of the Information Society is to enable all individuals to harness the benefits of technologies such as the Internet. In our quest for equitable access for all individuals to information and communication technologies (ICTs), it is becoming ever more apparent that all are not equal (Mansell, 2002). The impact of such disparity is often neither described nor quantified, but is usually extrapolated to the consequence of the individual being left behind, as well as more broadly to countries who are then unable to participate in the emerging global Information Society. This may have serious consequences, both economically and socially, for the nations concerned (Cullen, 2003).

In a country where adequate food, housing, electricity, security and medical aid are but mirages for the majority of citizens, as a result of poverty, unemployment, crime and/or illiteracy, the question of priorities is raised. Osin (1998) pertinently asks whether it is a justifiable investment to spend millions of dollars annually on technological development and use, instead of applying the money to improve the living conditions of those in dire need. Is it truly a need for these citizens, in spite of their basic needs not being met, to be computer literate or to have Internet access? Charles Kenny (Blackman, 2002: 1) argues that the poor face many different "divides", in terms of education, health care, etc, and that a logical answer to this question would be "no". Maslow's hierarchy of needs clearly indicates that the basic requirements for survival are not linked to any need for technological advancement or literacy. It is only when the basic needs for food and shelter have been satisfied that the needs for improvement, development, competition and self-realisation manifest themselves. This raises the question whether aid funds could not be used more "sensibly" by teaching these individuals skills such as financial independence and entrepreneurship. The answer may, ironically, lie in technology (Osin, 1998).

Thanks to the effective use of technology, many struggling small businesses have been afforded an opportunity to obtain a larger market share. The governments of developing countries could utilise these technologies to bring their economies up to par with those of developed countries. Thus the possibility arises not only to save money but also to generate it (Kenny, 2002). One of the main objectives of the Internet is to serve as a worldwide instrument for democracy (Centre for Democracy \& Technology, 2001) and sustainable development (Mansell, 2002). The Universal Declaration of Human Rights published in 1948 states that everyone has the right to freedom of expression and of speech. It is also provides for everyone to have an equal right, without reservation, to receive information and ideas by means of all media that exist. To realise this ideal, however, every individual on the planet should be able to state with conviction that he/she was given the opportunity. This would be the only way in which the Internet could realise its objective of becoming a true instrument of democracy and development.

The irony in terms of ICTs is that a digital divide may still exist even in countries where the infrastructures and technologies are freely available. The International Telecommunication Union's (ITU) ICT Development Index (IDI) revealed its 2014 "Measuring the Information Society (MIS) Report" that ranks 166 countries on their technology performance in areas such as ICT infrastructure, access, use and skills. The report indicated that South Africa has fallen further behind to po- 
sition 90 in this index, with an IDI value of 4.42 (which is under the global IDI average of 4.77). This has a further negative impact on the business landscape, as the majority of South African citizens do not possess the necessary ICT skills to make a meaningful contribution to the knowledge economy and become economically active citizens. However, the ITU stated that wireless broadband usage in South Africa is growing, as it reached $29 \%$ of mobile users in the country at the end of 2013. This is important for the region, which lacks a widespread and dependable fixed-broadband infrastructure.

Naidoo \& Saib (2013) emphasize the challenges in South Africa where a vast majority of people who lack basic ICT skills and resources. Research has identified certain groups of people who are slow to uptake ICTs, namely those with low incomes, little education or low literacy, the unemployed, the elderly, rural residents, disabled individuals, single parents, women and girls (Cullen, 2001; Campbell, 2001; Antonio \& Tuffley, 2014). Many of these factors, however, are interrelated, and should be addressed in a holistic and interdisciplinary manner. Park and Kwon (2013) focus their research on the multi-disciplinary aspects of social, economic, cultural and political relationships in addressing the digital divide. The status quo has a huge impact on the planning and rollout of infrastructure, as all major factors need to be identified and addressed in order to determine the feasibility of implementation plans.

It is mostly the wealthy and knowledgeable individuals who have easy, day-to-day access to the electronic information and communication systems such as the Internet (Nye, 2013). Whereas some citizens have unlimited access to ICTs on a daily basis, poor and resource-less citizens are marginalised and left ever further behind to struggle daily for survival (Kularski \& Moller, 2012). Apart from the perceived slow pace of the South African government's development of an ICT policy for the country, and the crumbling basic education system (Applied Research Unit at the Johannesburg Centre for Software Engineering, 2014), many factors are interrelated as a result of South Africa's unique apartheid history. Large numbers of people in South Africa have no faith in using technology, simply because they have never been taught how to use it and what benefits they stand to derive from its use. Developing countries such as South Africa rarely have the funds to subsidise practical and sophisticated school training (Nye, 2013); in developed countries, however, it is commonplace to have computers in every classroom. The current state of statefunded education and the lack the necessary socio-economic conditions results in the exclusion of a large section of the South African population from a proper education, one that would have enabled them to reap the benefits of the use of even basic technologies.

Another factor not often recognised is the high value placed on cultural traditions such as oral communication, which may well be neglected by ICTs. This relates primarily to a lack of relevancy for the audience; in other words, the technology does not meet the audience's cultural and/or ethical needs (Nye, 2013). It also relates to the lack of relevant content in the user's home language, since the majority of Web content is in English. The diversity of the South African population only serves to further complicate these issues, compared to other developing countries. This is illustrated by the fact that South Africa has no fewer than 11 official languages. Although English is generally used as the language medium on the Internet, most South African citizens choose to communicate in their mother tongue. Quite a few Afrikaans websites currently exist, but to find a Zulu, Xhosa or Sotho website is less common. As a result, less local content is produced, which makes the Web less relevant to these people's lives (Nye, 2013). This situation naturally results in a significant under-representation of non-English-speaking people among the world's Web users.

Most ICTs are considered tools in the provision of other priorities for countries, for example, the Internet itself is not an education, does not teach literacy and requires some level of skill to operate effectively (Cullen, 2003; Lewis, 2013). Holmer and Britz (2013) affirm that African countries have made tremendous strides in the last decade to address connecting people to the Internet. 
Africa still has a long way to go towards human capacity development. Once basic skills have been acquired, however, they may well serve as tools for education and sharing information, with the added advantage of reaching large numbers of learners (Mansell, 2002; Nye, 2013).

\section{Tertiary Institutions in South Africa as Drivers of Technology}

As students should all be literate and able to speak, write and understand English as an academic language, the level of education and language barriers are not obvious influencing factors in the technological usage patterns of the students of a higher education institution. Although South Africa is reported to be ahead of other Sub-Saharan African countries in terms of its access and utilization of ICTs (Barry, Chukwuma, Petitdidier, Cottrell \& Barton, 2011), numerous stumbling blocks still exist that hinder the access to and the usefulness of ICTs in South Africa. As a result higher education institutions in South Africa experience the presence of "digital strangers" (Czerniewicz \& Brown, 2012) who are students lacking both the experience and opportunities with ICTs and who had barely used a computer off-campus.

Many South African students "survive" their tertiary education because of bursaries and/or student loans, and do not always have the means to acquire educational necessities such as personal computers. Most campuses in South Africa, however, have information kiosks (Wilder, 2000: 4), computer laboratories and electronic library services available on campus, which give students free access to the Internet and e-mail services. Each student also receives a free e-mail address upon registration, which address he/she will keep for the remainder of his/her years of study. This serves to encourage not only electronic communication between students and lecturers but also the utilisation of online learning tools such as those provided by Blackboard.

Socio-economic circumstances plays a significant role in ICT access, as these students might have had access to technology (computers, telephones, etc) while on campus, but might not have the means to acquire these technologies after graduation. In South Africa, being a graduate does not guarantee employment as the high unemployment rate makes entering the job market an extremely challenging endeavour for young, inexperienced graduates.

The attitudes and self-perception of students of a tertiary institution with regard to their utilisation of technology are anticipated to be better than those of individuals who have had little or no contact with information systems. Owing to the fact that many South African university courses demand Computer and Information Literacy as compulsory modules in their curricula, students are trained from their first year to use computers, even if they have never had any previous experience with these systems. The result is more self-assured and competent users of technology once the students have graduated. It is expected that this confidence will greatly contribute to their willingness to utilise and embrace new technology as information and communication tools later in their lives, regardless of their gender and/or age.

A tertiary institution should therefore contribute as much as possible to the sustainability of its students' technology skills and access by creating the opportunities for them to participate in electronic communication (Barry, et al. 2011). Not only does this ensure the enhancement of the student learning experience, but it also contributes to bridging the digital divide in South Africa. Universities also benefit greatly if greater emphasis is placed on the rational and effective use of existing resources.

"Institutions that squander resources and supply sub-standard education should not be surprised if they continued to find resource mobilisation difficult" (The World Bank, 2000: 95). 
The appropriate, pedagogically sound use of ICTs for teaching and learning can be an important tool to speed up and simplify the process of mobilising scarce university resources as the application of these technologies is likely to pay dividends in a wide variety of areas, to the benefit of all stakeholders. As the higher education system in South Africa is under pressure to improve the quality of the education it provides, while at the same time increasing the number of students they educate (The World Bank, 2000: 50), other avenues to provide affordable, quality education need to be explored more urgently to meet these objectives.

\section{One of the University of Johannesburg's Initiatives to Address the Digital Divide}

In November 2010 the Council of the University of Johannesburg approved a set of eight "Strategic Thrusts" that would guide institutional decision-making for the years 2011-2020 (Barnard \& Van der Merwe, 2014). One of the Objectives of Strategic Thrust Eight - "Resources that support the University's fitness for purpose, support the achievement of the primary thrusts and facilitate a responsible and responsive institutional citizenship" - was the provision of Information and Communications Technology that "supports teaching and learning that is open and ubiquitous". The University recognized the need for careful planning and the dedicated use of its scarce resources to achieve this objective.

Its initial investment was in resources to expand its bandwidth capacity on and to each of its four campuses in Greater Johannesburg. By early 2013, the University, in conjunction with a consortium of South African universities had sufficient bandwidth to accommodate the dramatic growth in demand for bandwidth capacity for administrative, research and teaching purposes.

The next step in the strategic rollout was to provide wireless capacity on the four campuses. This was done in stages over a three-year period:

(i) Wi-fi "hotspots" were established on each of the campuses. Driven by student demographics and student mobility, studies were undertaken to determine the best location for such hotspots. Eventually, nine such hotspots were erected in 2011-2013, spread over the respective campuses. Their use by students was monitored.

(ii) Each of the student centers on the campuses was provided with wireless connectivity.

(iii) The four libraries on each of the campuses were provided with full-cover wireless connectivity. This project was completed in 2012.

(iv) A program was developed for the gradual provision of wi-fi connectivity in classrooms. Teaching, laboratory and tutoring venues were identified in consultation with teaching staff and implemented accordingly. By the end of 2013, all of the venues for first-year teaching on all of the campuses had been provided with wi-fi connectivity and roughly $65 \%$ of all teaching venues were thus covered.

(v) In 2013 a program was also completed to provide wi-fi access to all rooms in all student residences on and in the immediate vicinity of the four campuses, providing wireless connectivity to around 6500 resident students.

(vi) Electrical power points were installed at the hotspots and in each of the libraries and student centers to enable students to charge their devices on campus.

After a comprehensive impact study the University approved a policy in 2013 for the reasonable use of bandwidth by students. The important and liberal provisions of this policy are the following:

- They have free access to a quota of $5 \mathrm{~GB}$ of international bandwidth per month oncampus between 6:00-19:00 every day and to unlimited free access between 19:00-6:00 in the evenings. If they exceed the 5GB limit, their further use will be subject to a slower access speed; 
- The bandwidth "cap" can be lifted for students engaged in a particular research project in a particular module;

- All computers in the UJ libraries are exempt from a bandwidth "cap", but are subject to a time limit on use, as determined by the Head of the Library;

- All PhD students and academic staff have unlimited free access to international bandwidth;

- $\quad$ Although access to certain websites is blocked in terms of University policy (or access provided only for legitimate academic research), access to and use of the Internet is unrestricted.

The University has a large number of underprivileged students who cannot afford regular Internet access off campus. In light of this the University reached an agreement with Telkom, the state owned telecommunications provider, in late 2013 to provide a package deal to UJ students, which allows them to purchase a date bundle that allows them free and unlimited internet off-campus access to identified UJ websites via a $3 \mathrm{G}$ device, even if their data has expired. Discussions are ongoing with other service providers to provide further access to such underprivileged students.

Once the infrastructure provision, described above, was completed or well in hand, the next and important phase in the provision of ubiquitous access for teaching and learning purposes was initiated. This was namely to give effect to an integral component of UJ's teaching philosophy, namely "learning with technology", by requiring of students and staff to use handheld devices in the learning and teaching process. This, of course, is a multi-dimensional strategy that will be implemented over a period of years.

The first step in the implementation of such a policy was to oblige all first year students (some 10 500 ) in 2014 to have a handheld device as an essential pedagogical tool of learning in their firstyear modules. Giving effect to such a decision demanded careful planning by a range of roleplayers within and outside the institution. Some of the important strategic questions that needed to be answered were the following:

(i) What devices, with what specifications, were required?

(ii) How did the institution deal with those students (and estimated $25 \%$ of the first year student total) who were unable to afford to purchase a device?

(iii) What arrangements needed to be made to ensure that all teaching staff for first year students had access to devices?

(iv) What training needed to be undertaken to ensure that all staff and students were well versed in the use of devices as pedagogical tools/

(v) How would the project be financed?

(vi) What communications should go out, and to whom?

(vii) What logistical arrangements needed to be in place to ensure that all students had devices at the start of the academic year?

(viii) To what extent could the devices be used for e-books to replace hardcopy textbooks?

The planning was coordinated by a central committee, which reported to the Vice-Chancellor and the Management Committee. It comprised senior representatives of the Division for Academic Development and Support, the Division for Information and Communications Systems (ICS), the Operations Division and the Finance Division, as well as selected academics with a stated interest in learning and teaching technology.

\section{Devices}

Information on what devices would be appropriate and what minimum specifications were required was gathered from each of the nine faculties. Although there was a clear preference for 
tablets, this was not so in all of the faculties. Minimum specifications were drafted by the ICS Division and published.

Negotiations were entered into with a number of service providers to get the best deal for students and teaching staff. The negotiations were not always easy and ate into the time that was required for the devices to be ordered, delivered and distributed. It was important for the students to be provided with a choice between different devices (provided all complied with the minimum specifications), from entry level to top-of-the-range devices. It was found that there was a significant price differential between the different types of devices and that some providers were keener than others to negotiate terms for staff and students.

\section{Underprivileged students}

An important consideration that generated much discussion was how to deal with the reality that a large number of underprivileged students would not be able to afford to possess a device. A strategic decision was taken that the University would purchase devices for all those students who were unable to do so themselves. Of course, it was crucial that clear and implementable rules were established to determine whom the University would provide with a tablet and who would be expected to provide own resources for it.

The majority of the underprivileged students at UJ are funded by the state-funded National Student Financial Aid Scheme (NSFAS) for the duration of their studies. Students who apply for funding are assessed in terms of a "means test". This means test determines whether or not they qualify for funding. The funding criteria for a NSFAS loan was well known to the students and had been successfully implemented at UJ (and other institutions) for some years. UJ decided to adopt this means test for purposes of the technology strategy. In effect, therefore, those who were provided with funding by NSFAS automatically also qualified to be provided with a device by the University. Some 1900 students were thus identified. It was recognized that the application of this means test would disqualify a number of students who had little resources, but who nevertheless did not meet the criteria of the test. The too heavy burden that would have been placed on the university administration to administer a set of parallel criteria was deemed sufficient reason not to deviate from the NSFAS criteria. Students unable to afford a device still had access to the computers available to them in the so-called "computer laboratories" on each of the campuses.

These students were provided with entry-level devices. The service provider provided the top 500 students, in terms of their final grade 12-school results, with top of the range devices and access to further training opportunities.

\section{Provision of devices for teaching staff}

All teaching staff involved in teaching first year students was expected to be in possession of a device (preferably a tablet) for teaching purposes. The faculties were expected to provide the financing of such purchases and staff were given the same choices, as were the students. The source of funding was either from the research account of each individual academic or from faculty funds earmarked for teaching and learning purposes.

\section{Training}

Training in the use of the tablets for staff and students was provided by the Center for Academic Technologies in the Division for Academic Development and Support. It was logistically complex to provide substantive training to teaching staff in the appropriate use of technology for learning purposes; in particular to make teaching staff (with varying degrees of expertise in the use of technology) understand what the appropriate role of technology is in the learning and teaching process. Training sessions commenced in September 2013 and took place regularly. 
The provision of training to some 10500 first year students was logistically even more challenging. Students who had proven their ability in the use of technology, in assessments conducted as part of the registration process, were exempted from training. For the others training was conducted at all four campuses.

\section{Finance}

The provision of ICT infrastructure and of tablets to underprivileged students proved to be a costly exercise. The significant institutional expenditure on this project would be recurrent, as the strategy is rolled out to the entire university and as the infrastructural and resource demands grow. The Council of the University recognized the value of the strategic objective and has approved the expenditure as a recurrent expense.

\section{Logistics and communication}

The Operations, ICS and Academic Administrative Divisions managed logistics. Arrangements were made with the relevant service providers for the procurement, delivery and storage of the tablets and their collection by the students on stated dates and times and at identified points, subject to confirmation of their eligibility and to the signing of an agreement for using and looking after the tablet. Regular communication containing accurate and timely information was sent to both staff and students in the pre-registration period.

\section{E-books}

The use of tablets as a vehicle for e-books at better prices than hardcopy textbooks, and/or allowing for the better use of the e-book as a pedagogical tool than the hardcopy textbook, proved to be a fraught exercise. Numerous discussions were held between the Library, academic staff and publishers to secure e-books for students at competitive prices. The possibility of using Internet communication network technology for distribution and content management, a multi-purpose system developed by a UJ graduate and owned by the University, was also investigated. This proved a difficult exercise and no satisfactory arrangement has yet been arrived at.

It has been widely recognized that the rollout of the strategy to provide ubiquitous access to information and communication technology for first-year teaching and learning purposes has been a qualified success. The University has been acknowledged as a front-runner in South Africa in the development and implementation of this innovative strategy. Close management of the strategy, involving as it did a range of internal and external stakeholders and the personal oversight of the Vice-Chancellor, ensured that the implementation ran relatively smoothly.

\section{Challenges Going Forward}

The distribution of the tablets to the qualifying students generated a degree of apathy from many of the beneficiaries. While one would have expected such underprivileged students to grab the opportunity to possess a tablet that opened up so many avenues for them, educational and social, at no or minimal cost, this was not universally the case. Some $15 \%-20 \%$ of the students failed to collect their tablets at the appointed time and place, despite ample communication in this regard. They were collected only when the tablets were virtually thrust upon them. Those involved in the project struggled to understand this apathy. The explanation, when it came, was surprising. The students, already carrying the burden of under-privilege, resented the further confirmation of their status as "poor" and therefore as beneficiaries of University largesse. The possession of an entrylevel tablet (which was what the University was able to provide them) earmarked them, in the eyes of those who possessed better-branded products, as "poor" and deserving of sympathy. In a word, it was not "cool" to have such a tablet. 
Apathy was also encountered among the teaching staff. Despite much interaction with them and the provision of ample training opportunities, the actual number of staff who required their students to use tablets as an integral component of their learning in a particular module, remained much less than anticipated. It is certainly true that many of the academics were not prepared to sacrifice tried and tested teaching methods and regarded learning with technology as little more than high-tech gimmickry. Others, despite sufficient warning, did not find enough time (and, no doubt, inclination) to do the substantive revisions to the study material required for "proper" learning with technology. But evidence began to surface, as the project was unrolled that not a few of these academics simply resented the managerial imposition on the sanctity of the classroom. They baulked, not at the inherent virtue of the learning-with-technology methodology, but at a perceived top-down and generalized committee-based imposition of a methodology that did not originate in the heat of the academic crucible.

The division of labor between the various internal role-players was not as clear-cut as had been initially supposed. A determination of what applications could or should be downloaded onto the devices, and who should be responsible for the development of new or customized applications, was a matter of some contention between academics, academic development and support staff and ICS staff. Sensitive and difficult decisions on which students qualify for sponsored devices and which do not, generated contestation between academics, administrative and finance staff about the ultimate responsibility for such an important decision. Contentious also were decisions on the nature and content of study materials: the Library staff, Academic Development and Support staff and academic staff all claimed equally plausible stakes in the decision-making process. Senate grumbled at Management because it sought input from Senate only when the network of decisions on strategic implementation had already proceeded beyond the point of no return. Management grumbled at Senate because it was slow to recognize the clear reputational advantages to the University of fully embracing the strategy.

The University received strong support from external service providers, who were willing to offer their products to the students at competitive prices. Yet it became clear that much more could still be achieved for the students. This will be the case if all service providers are offered opportunities to market their products against a background of full knowledge of what the University seeks to achieve with its strategy of learning with technology. Equally important is collaboration between universities, either regionally or nationally, to secure ever better infrastructure and resources for its students at ever more competitive prices. There is a fine line between healthy competition between universities for innovative and quality educational offerings to attract good students and collaboration in the procurement and sharing of resources that best serve the interests of broader civil society.

\section{Conclusion}

The University was in the healthy financial position of being able to use its own resources to implement the strategy. Whether this is sustainable over the long term depends on a range of factors not always within the university's control. The demand for learning and teaching with technology will grow and with it the demand for resources. Resources for this strategy are but one of many competing demands for scarce resources. The need for an expansion of the national resource base for all of the universities, by means of a national technology strategy for teaching and learning, is clear and insistent.

It is clear that the digital divide is still very much a reality. As the example of the tablets project at the University of Johannesburg demonstrates, this is so even in an environment as privileged as a higher education institution. And the reasons for the maintenance of the divide are often not nearly as obviously economic as most commentators would have it: the efficacy of managerial interventions, the psychology of disadvantage and pedagogical merit play an important role. Con- 
certed efforts to bridge the divide or at the very least to plan for the reality of the divide, must take these factors into account.

The question remains, though, as to the size of the funding that is devoted to the training of disadvantaged and marginalised groups to acquire Internet access and skills. Technology alone is not a solution for the economic and social ills of the world, and those new technologies can co-exist alongside old technologies to achieve the same ends. Perhaps there is no solution to be had after all, and perhaps those initiatives currently in progress would not resolve the disparity in the short term. Perhaps the acquisition of technology skills in those who still lack the means to use such skills to their own and their community's material advantage creates in them a sense of frustration and antipathy towards the digital world that can have unintended and negative social and psychological consequences.

ICTs are not, or should not always be, the self-evident high funding priority in or for countries where food, sanitation and literacy are more basic and therefore more pressing needs. Such essential, survival-driven priorities are the ultimate drivers for the nature and extent of improved access to ICTs. If regard is had to the addressing sustainably the basic needs of the majority of inhabitants of these countries, it is probably more viable option to invest in training them in the simple skills of reading, writing and basic survival in order for them to learn how to sustain themselves. Their current need for technological advancement, their need to cross the digital gulf that divides them from more advanced others, is minimal. Before their basic requirements are not met, there would be little value to them for the tangible and meaningful introduction of information and communication technologies into their lives. This does not mean that concerted effort should not nevertheless be made to create awareness in them of the possibilities for selfsufficiency and independence the use of simple and effective technologies holds and that a technology infrastructure that underpins and reinforces such awareness should not be established. If dedicated human capacity development, awareness campaigns and the accompanying infrastructure were to succeed, they would slowly but surely result in systematic and rapid technological advancement over time.

If the situation in terms of limited or improper access to ICTs were not addressed and if it were allowed to continue, the "haves" and the "have-nots" situation would merely be aggravated. The current situation is untenable. It is imperative that new strategies custom-made for developing countries and individuals on the wrong side of the digital divide are developed and implemented. Such strategies must aim, not to remove, but to dissolve barriers and to lay the foundations upon which the bridging of the digital divide will occur. This, more so than un-nuanced investment in ever more advance technologies, will increase the tempo at which change occurs.

From the outcomes of the research, it is clear that bridging the digital divide needs a holistic, interdisciplinary approach that addresses the social, psychological, economic and components of society, as much as, or even more so, than the technology driven components.

\section{References}

Antonio, A. \& Tuffley, D. (2014). The Gender Digital Divide in Developing Countries. Future Internet, 6(4), 673-687.

Applied Research Unit at the Johannesburg Centre for Software Engineering (JCSE). (2014). Annual ICT Skills Survey 2014. Retrieved November 26, 2014, from http://www.jcse.org.za/applied-research

Barnard, Z. (2005). Disseminating Information to Alumni of the University of Johannesburg. Masters dissertation. South Africa: University of Johannesburg.

Barnard, Z., \& Van der Merwe, D. (2014). From local imperative to global significance: the University of Johannesburg scenario. The Business and Management Review, proceedings of the International Con- 
ference on Business and Economic Development (ICBED), March 2014, New York, Volume 4 No. 4 , pp. 309-320.

Barry, B., Chukwuma, V., Petitdidier, M., Cottrell, L., \& Barton, C. (2011). Digital divide in sub-Saharan Africa universities: Recommendations and monitoring. In atIST-Africa 2008 Conference \& Exhibition, Windhoek, Namibia.

Blackman, C. (2002). Bridging the digital divide - a costly mistake? Info, 4(3).

Campbell, D (2001). Can the digital divide be contained? International Labour Review, 140(2), 119-141.

Charp, S (2001). Bridging the digital divide (industry trend or event). Technological Horizons in Education, 28(10), 1-3.

Cullen, R. (2001). Addressing the digital divide. Online Information Review, 25(5), 311-325.

Czerniewicz, L. \& Brown, C. (2012). The habitus of the digital "strangers" in higher education. British Journal of Educational Technology, 44(1), 44-53.

Goodrick, J., \& Srivastava, L. (2002). Licensing of third-generation (3G) mobile. Info, 4(1), 48-55.

Holmer, M. \& Britz, J.J. (2013). When the last mile become the longest mile: A critical reflection on Africa's ability to transform itself to become part of the global knowledge society. Journal of Appropriate Librarianship and Information Work in Southern Africa, 46, 117-134.

International Telecommunications Union. (2014). Measuring the Information Society Report 2014. United Nations Specialized Agency. Retrieved November 26, 2014, from http://www.itu.int

Kenny, C. (2002). Should we try to bridge the global digital divide? Info, 4(3).

Kularski, C. \& Moller, S. (2012). The Digital Divide as a continuation of traditional systems of inequality. Sociology, 5151, 1-23.

Lewis, C. (2013). Universal access and service interventions in South Africa: Best practice, poor impact: challenges in leadership of ICT policy and e-development. African Journal of Information and Communication: Leadership in the Electronic Age: a Broad Inter-Disciplinary Practice, 3, 95-107.

Mansell, R. (2002). Constructing the knowledge base for knowledge-driven development. Journal of Knowledge Management, 6(4), 317-329.

Naidoo, S., \& Saib, M. O. (2013). Bridging the digital divide with changing information literacy models in post-apartheid South Africa. Worldwide Commonalities and Challenges in Information Literacy Research and Practice, 397, 184-189.

Nye, B.D. (2013). ITS and the digital divide: Trends, challenges, and opportunities. Artificial Intelligence in Education, 7926, 503-511.

Osin, L. (1998). Computers in education in developing countries: Why and how? Education and Technology Series, 3(1).

Park, J., \& Kwon, Y. (2013). New stratification perspectives on the digital divide. International Journal of eGovernance and Networks, 1(1), 24-44.

Warshauer, M. (2002). Reconceptualizing the digital divide. First Monday, 7(7).

Wilder, R. (2000). Bridging the digital divide in higher education. Educase 2000: Served with Southern Charm Part 2. Library Hi Tech News. 


\section{Biographies}

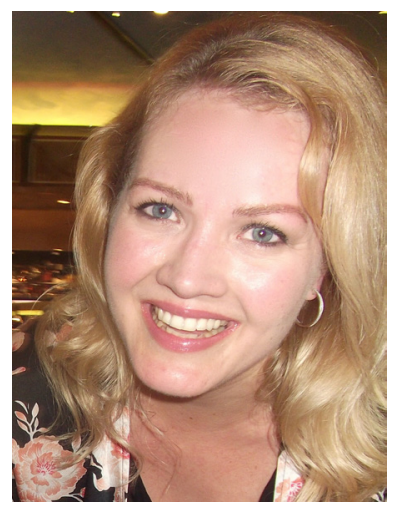

Dr Zenia Barnard is the Founder of Gradnet (in partnership with Google), a spin-off company resulting from her doctoral research; a company she sold in 2012. Her field of expertise is Information Science with a focus on Knowledge Management, ICTs, Web technologies and Innovation Management. She values action research for practical application in support of a dynamic and sustainable world. She is currently a part-time senior lecturer and postdoctoral fellow at the University of Johannesburg researching an "Interdisciplinary Paradigm for Knowledge and Innovation Management".

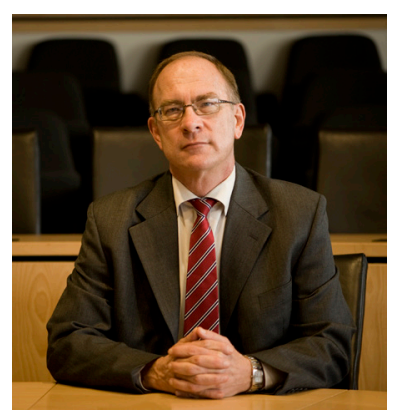

Prof Derek van der Merwe was a Professor of Law and Dean of the Faculty of Law before becoming Deputy Vice-Chancellor at the University of Johannesburg. He served for 5 years as Pro Vice-Chancellor of the University and, at the time of his retirement from UJ, was the Deputy Vice-Chancellor: Strategic Services. He is currently emeritus professor in the Faculty of Law. His research interests include legal theory, legal history, diversity and strategic management. 